\title{
A rare case of leaking abdominal aneurysm presenting as isolated right testicular pain
}

\author{
P.A. Sufi, FRCS (Gen), MS, FRCS (RCS of Eng)
}

\begin{abstract}
An abdominal aortic aneurysm (AAA) is not usually considered in the differential diagnosis of isolated right testicular pain. We describe a patient who did present with isolated acute right testicular pain as the sentinel feature of a leaking AAA. In the patient group with right testicular pain, consideration of a leaking AAA should be added to the differential diagnosis. An adverse outcome can be avoided by timely diagnosis and intervention.
\end{abstract}

Key words: right testicular pain, leaking aortic aneurysm

RÉSUMÉ

On n'envisage habituellement pas un anévrisme de l'aorte abdominale (AAA) dans le diagnostic différentiel d'une douleur isolée au testicule droit. Nous décrivons un patient qui s'est présenté avec une douleur aiguë isolée au testicule droit comme caractéristique sentinelle d'un AAA avec fuite. Chez les patients qui présentent une douleur au testicule droit, il faut ajouter au diagnostic différentiel la possibilité d'un AAA avec fuite. Le diagnostic et l'intervention rapides peuvent permettre d'éviter un résultat indésirable.

\section{Introduction}

An abdominal aortic aneurysm (AAA) is a potentially serious disease that typically develops in patients over 50 years of age and is more frequently seen in association with hypertension or a familial history of aneurysm. In asymptomatic patients, it may be detected during a routine screening abdominal ultrasound. Ruptured or leaking aneurysms can be fatal unless treated swiftly. Common presenting features are abdominal or back pain and a pulsatile abdominal mass in association with hemodynamic instability or shock.

On rare occasions, left testicular pain may accompany other more classic symptoms of a leaking AAA. ${ }^{1-4}$ Because the aorta lies to the left of the midline, atypical symptoms are usually localized in the left side. The diagnosis is commonly confused with mechanical lumbar back pain, renal colic, diverticulitis and incarcerated hernia. ${ }^{5}$ Left-sided and bilateral testicular pain due to AAA has also been described in the literature. ${ }^{6} \mathrm{~A}$ review of the literature could not identify any report of patients with leaking aneurysms presenting with isolated acute right testicular pain. This case report is about such a presentation.

\section{Case Report}

A 62-year-old delivery male presented to the accident and emergency department of Yeovil District General Hospital,

From the Department of Surgery, Royal Free and University College Medical School, London, UK.

Received: May 18, 2006; revisions received: Oct. 13, 2006; accepted: Oct. 18, 2006

This article has been peer reviewed.

Can J Emerg Med 2007;9(2):124-6 
UK, with a 6-hour history of progressively severe right testicular pain that did not respond to acetaminophen and ibuprofen.

The patient denied having any history of trauma, casual sex, dysuria, frequency or haematuria. He had a past medical history of hypertension, right total knee replacement for osteoarthritis and juvenile osteoporosis. His regular list of medications included ramipril and diclofenac. $\mathrm{He}$ also used Co-dydramol (dihydrocodeine tartrate $10 \mathrm{mg}$, Paracetamol $500 \mathrm{mg}$ ) on occasion for his osteoarthritis. He was a non-smoker and drank alcohol socially.

On physical examination, the patient was overweight $(130 \mathrm{~kg})$, and his vital signs were normal (pulse 87 beats / min, blood pressure [BP] 147/68 mm Hg, temperature $36.8^{\circ} \mathrm{C}$, respiration 24 breaths $/ \mathrm{min}$ and $\mathrm{SaO}_{2} 98 \%$ on room air). The patient appeared generally well; examination of his abdomen, urogenital tract and lumbo-sacral spine were unremarkable. Initially, the cardiovascular system was not formally examined. Scrotal examination showed no evidence of trauma, inflammation or enlargement of the testis. A bedside urinalysis revealed only minor proteinuria.

The patient was initially diagnosed with right epididymo-orchitis. Before deciding to discharge the patient with antibiotics, we sought a urology-surgical consultation to exclude the possibility of testicular torsion or torsion of a testicular appendage.

When the patient was evaluated by the urologistsurgeon 2 hours later, he complained of a new right flank pain in addition to his existing right testicular pain. His vital signs had also changed slightly (pulse 98/min and a slightly narrowed BP 130/85 mm Hg). A repeat examination of the abdomen and scrotum again revealed no abnor-

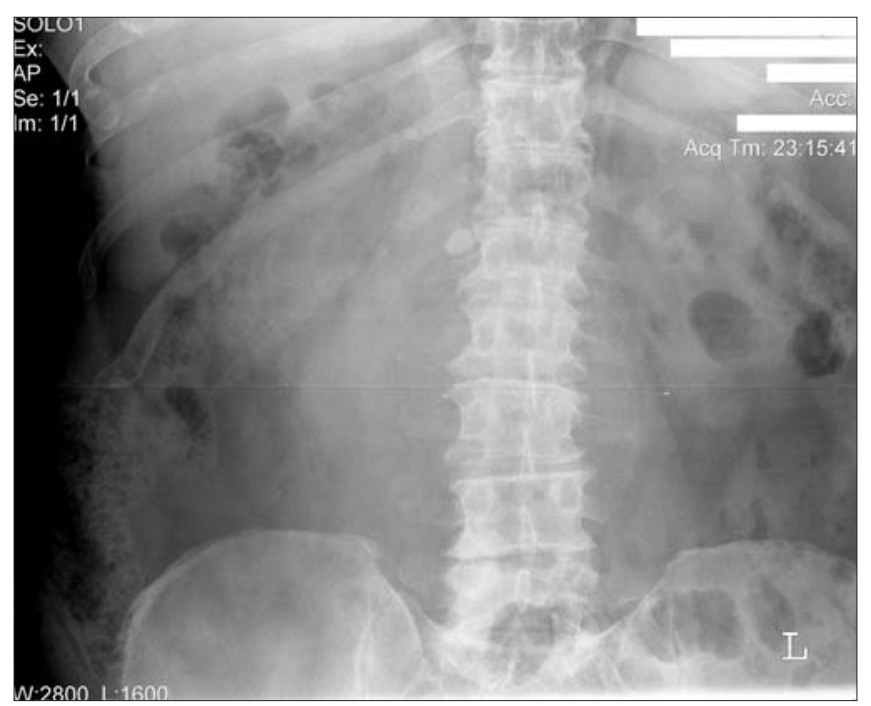

Fig. 1. Plain abdominal x-ray. mality. There was no pulsating abdominal mass or evidence of peripheral emboli. All peripheral pulses were present and symmetric. Blood tests included hemoglobin $12.6 \mathrm{gm} / \mathrm{dl}$, white blood cell $14.3 \times 10^{9} / 1$, platelet $1.8 \times$ $10^{12} / \mathrm{l}$, urea $12 \mathrm{mg} / \mathrm{dl}$, creatinine $94 \mathrm{mmol} / \mathrm{l}$ and international normalized ratio 1.3. The surgeon suspected the patient had a right ureteric stone and ordered an intravenous urogram. The initial plain film revealed calcification consistent with an AAA (Fig. 1). A contrast CT scan of the abdomen was immediately requested and revealed an $8.9 \mathrm{~cm}$ leaking AAA associated with a large hematoma in the right retroperitoneum (Fig. 2).

The patient remained hemodynamically stable and was transported to the regional vascular unit, where he underwent an emergency laparotomy 12 hours after the onset of his symptoms and 6 hours after initial hospital presentation. A leaking AAA with a large right sided hematoma was confirmed during surgery. The aneurism was successfully repaired, and the patient recovered uneventfully.

\section{Discussion}

Acute scrotal pain is a potential surgical emergency. Common causes include trauma, testicular torsion, torsion of testicular appendage and epididymo-orchitis. ${ }^{7}$ Uncommon causes include leaking AAA and testicular microlithiasis. ${ }^{8}$ A ruptured or leaking AAA is an uncommon surgical emergency with a high mortality rate, and survival for

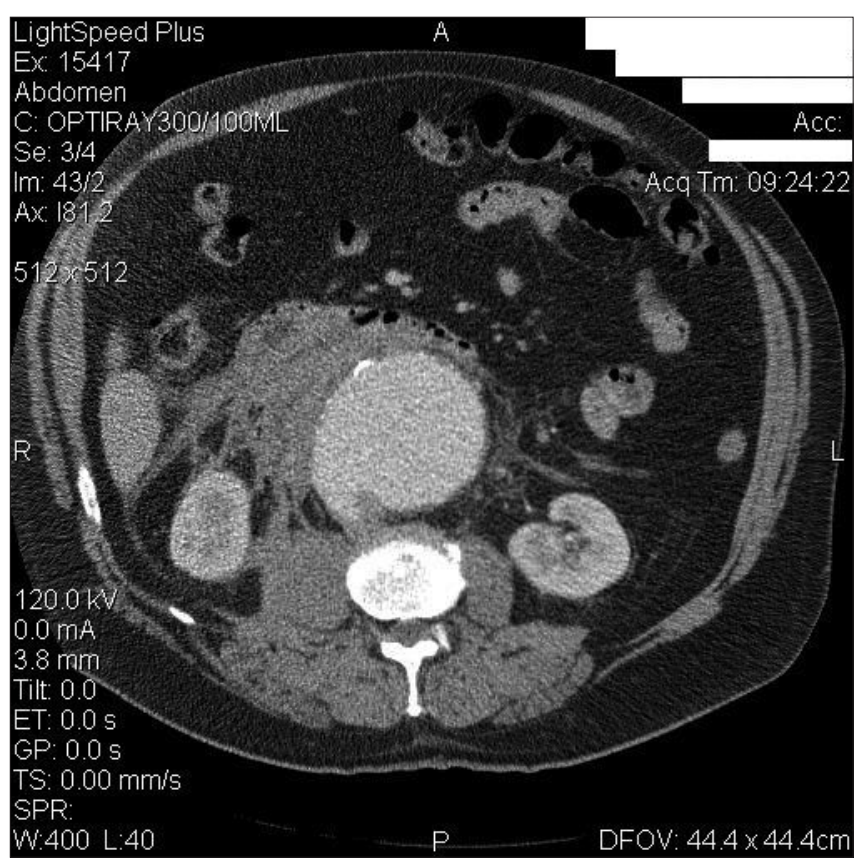

Fig. 2. Abdominal CT scan showing hematoma on the right side. 
those reaching the hospital alive is approximately $50 \% .^{9}$ Most patients are older than 50 years of age and present with abdominal pain radiating to the back in association with a pulsatile abdominal mass and hypovolaemic shock. ${ }^{9}$ Rarely, presenting symptoms can mimic renal colic, testicular torsion, diverticulitis, gastrointestinal hemorrhage or spinal arthritis. ${ }^{9,10}$ Diagnostic delay can adversely affect survival. ${ }^{11}$

The aorta usually lies to the left side of the midline in the retroperitoneum. Consequently, retroperitoneal hematoma irritating the lumbar plexus and the genito-femoral nerves have generally been reported on the left side. ${ }^{12}$ A leaking AAA is often suspected in the presence of left flank and groin pain, right buttock and hip pain in association with shock, or lower abdominal pain radiating to the right testi$\mathrm{cle}^{1,13}$; however, isolated, acute, right testicular pain in the absence of other symptoms or signs has not been previously reported. It is important to consider this diagnosis in the appropriate patient group.

\section{Conclusion}

This case demonstrates that leaking AAA should also be considered in the differential diagnosis of isolated, rightsided testicular pain in patients aged 50 years and older who have normal genitalia on examination. An emergency bedside ultrasound or an unenhanced CT scan may be indicated in these patients. Early suspicion may help avoid unnecessary delays in instituting the appropriate investigations and treatment in future patients with similar symptoms.

Competing interests: None declared.

\section{References}

1. Klapman MJ. Ruptured abdominal aneurysm with pain in the testicle. Calif Med 1960;92:163-4.
2. Artman MR, Burkle FM Jr. Acute abdominal aortic aneurysm presenting as isolated testicular pain. Am J Emerg Med 1987;5: $45-7$.

3. O'Keefe KP, Skiendzielewski JJ. Abdominal aortic aneurysm rupture presenting as testicular pain. Ann Emerg Med 1989;18: 1096-8.

4. Cawthorn SJ, Giddings AE, Taylor RS, et al. Isolated testicular pain: an unrecognized symptom of the leaking aortic aneurysm. Br J Surg 1991;78:886-7.

5. Chan-Tack KM. Aortic dissection presenting as bilateral testicular pain. N Engl J Med 2000;343:1199.

6. Ratzan RM, Donaldson MC, Foster JH, et al. The blue scrotum sign of Bryant: a diagnostic clue to ruptured abdominal aortic aneurysm. J Emerg Med 1987;5:323-9.

7. Koester MC. Initial evaluation and scrotal pain. J Athl Train $2000 ; 35: 76-9$

8. Venketraman S, Gray JP, Evans PA. Scrotal pain in the absence of torsion; need for vigilance. Emerg Med J 2003;20:104-5.

9. Marston WA, Ahlquist R, Johnson G Jr, et al. Misdiagnosis of ruptured abdominal aortic aneurysm. J Vasc Surg 1992;16:17-22.

10. Acheson AG, Graham AN, Weir C, et al. Prospective study on factors delaying surgery in abdominal aortic aneurysm. J R Coll Surg Edinb. 1998;43:182-4.

11. Borrero E, Queral LA. Symptomatic abdominal aortic aneurysm misdiagnosed as nephrolithiasis. Ann Vasc Surg. 1988;2:145-9.

12. Scherf FG, Karger B, Pastor J, et al. Left-sided flank pain in coincident infrarenal aortic aneurysm and left-sided nephropathy. Urologe A 1996;35:342-4.

13. Mahmood F, Ahsan F, Hockey M. Ruptured abdominal aortic aneurysm presenting as buttock pain. Emerg Med J 2005;22: 453-4.

Correspondence to: P.A. Sufi, Department of Surgery, Royal Free and University College Medical School, Pond Street, London UK NW3 2QG; pasufi@netscape.net 